\title{
THE PHONETIC ASPECT OF TEACHING RUSSIAN TO TURKISH STUDENTS
}

\author{
Zulfiya ŞAHİN ${ }^{1}$
}

\begin{abstract}
The article considers the phonetic peculiarities of the formation process of the Russian language listening and pronunciation skills among Turkish students, beside this, is paying attention to the process of cross-language interference and inconsistencies of the two language phonetic systems. Highlighting inconsistencies, the author tries to point out the main causes of phonetic disorders in relation to the Russian pronouncing standards. Along with this article provides recommendations for setting sounds of the Russian language.
\end{abstract}

Keywords: Russian as a Foreign Language, Phonetics, Russian, Turkish.

Şahin, Zulfiya. "Foneticheskij Aspekt Processa Prepodavanija Russkogo Jazyka Turetskim Studentam". Ídil 3.11 (2014): 191-203.

Şahin, Z. (2014). Foneticheskij Aspekt Processa Prepodavanija Russkogo Jazyka Turetskim Studentam. İdil, 3 (11), s.191-203.

${ }^{1}$ Öğr. Görevlisi, Dr. Ankara Üniversitesi, Dil ve Tarih-Coğrafya Fakültesi, Rus Dili ve Edebiyatı Bölümü,aluzank@.gmail.com 


\title{
ФОНЕТИЧЕСКИЙ АСПЕКТ ПРОЦЕССА ПРЕПОДАВАНИЯ РУССКОГО ЯЗЫКА ТУРЕЦКИМ СТУДЕНТАМ
}

\section{РЕЗЮМЕ}

В статье рассматриваются фонетические особенности процесса формирования слухопроизносительных навыков русского языка у турецких студентов, а также рассматривается процесс межъязыковой интерференции и уделяется внимание несоответствиям фонетических систем двух языков. Выделяя несоответствия, автор пытается указать на первопричины фонетических нарушений, по отношению к русским орфоэпическим стандартам. Вместе с этим в статье даются рекомендации по постановке звуков русского языка. Турецкий.

Ключевые слова: Русский Как Иностранный, Фонетика, Русский,

\section{TÜRK ÖĞRENCILERE RUSÇA DİL ÖĞRETIMININ SESBILIMSEL YÖNÜ}

\begin{abstract}
ÖZET
Makalede Türk öğrencilerin Rusça öğrenim esnasında işitme ve telaffuz edebilme gibi becerilerin oluşumunun özellikleri incelenmektedir, ayrıca diller arası girişim süreci ve iki dilin sesbilimsel farklılıklar araştırılmaktadır. Yazar farklılıkları tespit ederek, Rusça doğru telaffuz kurallarına uygun olmayan sesbilimsel bozuklukların asıl nedenlerini tespit etmeye çalışmaktadır. Ayrıca çalışmada doğru telaffuz oluşturmanın tavsiyelerini de içermektedir.
\end{abstract}

Anahtar sözcükleri: Yabancı Dil Olarak Rusça, Sesbilim, Rusça, Türkçe. 


\section{Введение}

В лингвистике фонетику, как правило, определяют как науку о звуках речи. Данное определение в первую очередь опирается на этимологию слова «фонетика» - звуковой. Но границы данной науки простираются гораздо шире звуковых границ языка. Общая фонетика тесно связана с такими науками как физика, физиология и лингвистика, частный же раздел взаимодействует с лексикологией, морфологией и синтаксисом и др. лингвистическими направлениями. «Значение фонетики как научной дисциплины определяется, прежде всего, тем, какое значение имеет в языке его звуковая сторона. Важнейшая роль обуславливается тем, что общение между людьми, средством которого является язык, осуществляется именно через звуковую сторону и благодаря ей. Звуковая сторона составляет необходимую часть языка; только она и делает возможным его развитие, передачу от поколения к поколению. » (Зиндер, 1979:4)

Как было отмечено Л.Р. Зиндером и другими лингвистами, язык и, в частности, его звуковая сторона являются средством общения. Процесс общения людей крайне сложный многоэтапный механизм получения, обработки и восприятия информации. Общение на неродном языке вдвойне сложный механизм, поскольку помимо перечисленных этапов включается этап соотнесения понятий иностранного и родного языка. Хотелось бы заметить, что часто под общением подразумевается обмен информацией, что совершенно справедливо, однако понятие общения несколько шире, чем простой обмен информацией. Любая информация исходящая от человека несет на себе помимо информационной нагрузки субъективный оттенок и целью общения является не только обмен информацией, но и обмен субъективной точкой зрения и как следствие воздействие на собеседника. В этой связи актуально высказывание Н.А. Любимовой «Результативность и эффективность общения на неродном языке, исполнение социальной роли говорящего во многом определяется качеством фонетического оформления речи иноязычных, так как целью общения является не только достижение адекватного понимания, но и воздействие собеседников друг на друга в процессе данной деятельности» (Любимова, 2011:10). А по мнению академика Л.В. Щербы «Для того чтобы кого-либо в чём-либо убедить, публично или в частном разговоре, надо говорить выразительно и не смешно» (Любимова/Щерба, 1974:161)

Конечно, носитель языка с первых секунд общения понимает, что перед ним иностранец, и начинает воспринимать неидеально фонетическиоформленную речь говорящего крайне толерантно. Но в данном случае нельзя 
говорить о том, что это никак не влияет на общение. Еще Р.И. Аванесов говорил о том, что «любые отклонения от орфоэпических норм отвлекают слышащего и затрудняют понимание». (Аванесов, 1972:13) В данном случае успех общения во многом зависит от возможности реципиента реконструировать нестандартные звуковые формы. В процессе реконструкции фонетической формы реципиент вынужденно обращается к экстралингвистическим сторонам общения и компенсирует понятийную составляющую с помощью жестов, мимики и т.д.

Н.А. Любимова в своих исследованиях отмечает два вида фонетических нарушений: «несущественные» и «грубые». К несущественным исследователь относит нарушения речи, которые не нарушают понимание, а к грубым те нарушения, которые препятствуют общению. Первые воспринимаются носителями языка как допустимые. (Любимова, 2011:11) Нужно отметить, что допустимость или недопустимость нарушений регулируется дифференциальными, а порой и релевантными признаками фонем, каждого конкретного языка.

Целью написания данной статьи является вычленение фонетических трудностей и ошибок турецких студентов в процессе обучения русскому языку, большая часть которых возникает в результате межъязыковой фонетической интерференции - сложного механизма взаимодействия звуковых норм разных языков. Не лишним будет заметить, что интерференция может происходить не только под влиянием родного, но и ранее изученных иностранных языков. Опираясь на более чем десятилетний опыт преподавания русского языка в тюркоязычной аудитории, ниже будут перечислены основные фонетические трудности, с которыми сталкиваются турецкие студенты.

Хотелось бы заметить, что работ посвященных сравнительной русскотурецкой фонетике крайне мало, отдельные вопросы сравнительной русской и турецкой фонетики были освещены в работах В.А. Горделевского (1928), Х. Джевдет-Заде и А.Н. Кононова (1934), Р.С. Кадырова (1999) и Р.Г. Раджабалиева (2002). В перечисленных исследованиях уделялось внимание теоретическому сравнению фонетических систем двух языков. Новизна же данной статьи в том, что в ней рассматриваются в первую очередь практические сложности, наблюдаемые в процессе обучения. 


\section{1. Фонетические трудности как следствие разностей фонетических систем русского и турецкого языков}

Как было сказано выше, фонетические нарушения в процессе обучения иностранному языку возникают в результате интерференции, то есть в результате наложения фонетической системы одного языка на фонетическую систему изучаемого языка. Таким образом возникает вопрос о соответствии и несоответствии фонетических норм двух языков. Соответствие фонетических норм заметно облегчает изучение иностранного языка и в данном случае можно говорить о положительной интерференции. При соответствии в процессе овладения иностранным языком обучающийся пользуется уже существующими слухопроизносительными навыками, не испытывая надобности в освоении новых. Но фонетические нарушения возникают как раз при противоположном положении дел, т.е. при несоответствии. Именно несоответствия фонетических норм ведут к звуковым нарушениям и имеющиеся слухопроизносительные навыки становятся недостаточными для реализации произносительных стандартов изучаемого языка. И так как целью нашей статьи является выявление фонетических трудностей турецких студентов в процессе обучения русскому языку, речь, в первую очередь, пойдет о несоответствиях фонетических систем турецкого и русского языков.

1.1. И. Эргенч, в своем исследовании по турецкой фонетике, говорит: «типичной особенностью турецкого языка является наличие большого количества гласных.» (Эргенч, 2002:18) Справедливость сказанного подтверждает наличие 8 гласных (/a/, /u/, /e/, /i/, /o/, /ö/, /ü/, /1/) в турецком и 6 гласных (/a/, /y/, /э/, /и/, /o/, /ы/) в русском языке. Д. Аксан, говоря о турецких гласных, отмечает следующее: «Основные фонетические особенности (турецкого языка) связаны с гласными... Гармония гласных определяет многие фонетические и морфологические процессы турецкого языка » (Аксан,1978:11). В турецком языке существует два вида гармоний. Первая и основная гармония - гармония велярных и палатальных гласных, предполагает, что если слово в языке начинается слогом, содержащим велярную гласную, то все остальные слоги должны содержать только велярную гласную, если же первый слог содержит палатальную гласную, то последующие то должны быть палатальными. Второй вид гармонии - это лабиальная и нелабиальная, работающая по тому же принципу, что и первая. Таким образом, распространённое в русском языке расположение гласных в слове, является нетипичными для исконно турецких слов. В заимствованных словах турецкого языка гармония может нарушаться, что служит 
положительным моментом в процессе развития навыка произнесения нестандартных сочетаний.

Говоря о разностях фонетических систем русского и турецкого языков нужно отметить разнонаправленность большей части фонетических процессов в этих языках. Опираясь на слова Д.Аксана, что сингармония, присутствующая и определяющая большую часть фонетических процессов в турецком языке, является «примером полной и большей частью прогрессивной ассимиляции» (Аксан, 1978:20), можно сделать вывод, что в фонетических процессах турецкого языка превалирует прогрессивный характер. В то время как в русском языке фонетические процессы большей частью имеют регрессивный характер. Этот момент является важным для понимания причины фонетических нарушений, в нашем случае, турецких студентов. В частности это является одной из причин стремления учащихся смягчить согласную после «мягких» гласных в таких словах как мел, лёг, кинул, тёк и.др. (в речи

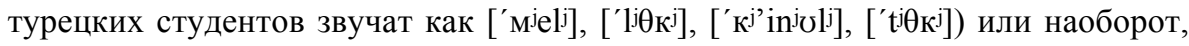
веляризировать мягкий конечный согласный после «твердой» гласной, например в таких словах как даль, лань, дать, лось и др. (в речи студентов [dal], [lan], [dat], [los]). Конечно нужно отметить, что в обоих языках имеют место быть фонетические процессы и другой направленности, так в турецком есть примеры регрессивной ассимиляции, а в русском есть примеры прогрессивной, но они не меняют общую направленность.

1.2. Другой особенностью фонетической системы турецкого языка является закон полногласия, не допускающий стечение двух гласных или согласных в одном слоге. Д. Аксан конкретизирует эту фонетическую особенность: «Для турецкого языка является характерным наличие только одного согласного в начале слова.» (Аксан, 1978:50) Таким образом при произнесении турецкими студентами русских слов, изобилующих стечением согласных в начале слова или середине, с позиции русской орфоэпии наблюдаются определенные фонетические нарушения. В частности появление протетического или эпентетического гласного между согласными. Как правило роль достижения полногласия берут на себя гласные /i/, /1/ или /u/. (Хатипоглу, 1961:22) Например при произнесение таких слов как: предпринимательство, штрих, шквал, всплеск, вздремнуть, всхрапнуть, встреча, вздрогнуть, здравствовать, мудрствовать, милосердствовать, иприи, контрпредложение, усердствовать и др. появление протетического или эпентетического гласного между согласными практически неизбежно.

Появление протезы или эпентезы в турецких словах иностранного происхождения подробно описывалось в работах Д. Аксана (1978), Д. Дени 
(1941), А.Н. Кононова (1956), Х.Т. Бангуоглу (1974), М. Эргина (1958) и д.р. Говоря о первопричинах этого явления в турецком Д. Аксан ссылается на закон экономии в языке. (Аксан, 1978:49)

1.3. Среди других особенностей русского языка следует назвать наличие согласного звука /ж/ в твердом варианте в большинстве русских слов. «Фонемы «ж, ш, ц, ч’» нормально не имеют в русском литературном языке параллелей по твердости и мягкости. При этом «ж, ш, ц» оказываются нормально твердыми, а «ч'» - мягкой.» (Щерба, 2007:170) В свою очередь в турецком языке орфоэпической нормой этого согласного признается его мягкий вариант (Эргенч, 2002:273). Н. Селен же в своем описании согласных говорит об отсутствии звонкого /ж/ в фонетической системе турецкого языка. В редких примерах звук/ж/ встречается в начальной и средней позиции в словах иностранного происхождения. (Селен, 1979:101)

Таким образом в речи тюркоязычных студентов на месте твердого согласного /ж/ часто можно услышать произнесении мягкого варианта этого согласного. Развивая тему мягкости и твердости русского согласного /ж/ Л.В. Щерба говорит: «Однако рядом с «ш», «ж» твердыми у значительной части русских говорящих на литературном языке, имеются еще самостоятельные двойные мягкие «шьшь», «жьжь»... вожжи (в произношении одних «вожжы», в произношении других «вожьжи». ....Учитывая все это и имея в виду наших националов, обучающихся русскому языку, иностранцев и глухонемых, я предпочитаю не включать двойных мягких «шьшь» и «жьжь» в основной список фонем русского языка, сознательно предрешая этим до определенной степени и орфоэпический вопрос» (Щерба, 2007:171, 172) Следуя опыту знаменитого русского фонетиста, при обучении турецких студентов произношению русского /ж/ логичнее делать акцент на его твердость, учитывая, что навыки произнесения мягкого варианта уже существуют.

Сравнивая особенности русского /ж/ [こ̌] (в некоторых источниках, и, в частности, в международной фонетической системе (IPA), основной аллофон русского /ж/ классифицируется как ретрофлексивный [z], что отчасти справедливо, так как в некоторых позиционных вариантах он действительно присутствует. Однако опираясь на мнение Л.Р. Зиндера (1979:157) и Н.А. Любимовой (2011:86), мы рассматриваем его как какуминальный) и турецкого /j/ [3] (у И. Эргенч он классифицируется как апикальный (Эргенч, 2002:273), у Н. Селен мы встречаем его дорсальный вариант (Селен,1979:101)) не лишним будет обратить внимание на артикуляционные особенности обоих звуков. Принимая за основу таблицу Л.В. Щербы русский [ž] можно классифицировать как какуминальный, щелевой, шумный, серединный, 
двухфокусный; турецкий [3] как апикальный, щелевой, шумный, серединный, двухфокусный (Зиндер, 1979:150). Продолжая тему твердости мягкости, Л.Р. Зиндер говорит о следующем: «Двухфокусные со вторым задним фокусом, хотя в них, как в соответствующих какуминальных, поднята

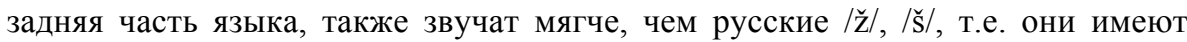
более высокую тембральную окраску. Это объясняется тем, что при апикальной артикуляции не образуется значительного углубления между передним и задним фокусами.» (Зиндер, 1979:159)

Суммируя все вышесказанное, для правильного орфоэпичного русского /ж/ турецких студентов надо научить не подменять какуминальный тип, более привычным апикальным или дорсальным. Для этого в момент произнесения /ж/ нужно поднять и загнуть, насколько это возможно, язык в сторону нёба, что исключит возможность подъема среднего участка спинки языка, т.е. возможность его смягчения. Основным при коррекции является контроль над средней частью спинки языка, а именно её низкое положение. Заметим, что твердый вариант русского /ж/ это в первую очередь орфоэпическая нора, произнесение мягкого варианта этого согласного не приводит к нарушению смысла.

1.4. Аффриката/ц/ отсутствует в турецком языке. Часто в процессе преподавания русского языка для объяснения артикуляции /ц/ иноязычным студентам данная аффриката объясняется как сложение смычного /T/ и щелевого /c/. В связи с этим актуально высказывание Н.А. Любимовой: «Методически и лингвистически неправильно толковать механизм образования /ц/ как сложение двух звуков /T/ + /с/. Это может провоцировать следующее: 1) произнесение /ц/ как сочетание этих звуков, непременно сопровождающегося гласной вставкой (о[тс]а [тс]ырк; 2) заменену сочетания /тc/ на аффрикату (например на стыке приставки и корня)» (Любимова, 2011:116). Первое фонетическое нарушение очень часто можно наблюдать в тюркоговорящей аудитории. Как уже говорилось прежде, полногласие в турецком языке не допускает стечение двух согласных, таким образом при подобном толковании аффрикаты /ц/ между смычным и щелевым звуками непроизвольно появляется эпентетическая гласная /ы/. Во избежание данного нарушения правильнее делать акцент на восприятие данного звука как одного, при этом подробно описывая его артикуляцию. По мнению Л.Р. Зиндера «итак, аффриката содержит два элемента смычный (но не взрывной) и щелевой. Это и дало повод для традиционного определения аффрикат, как слитных звуков, представляющих соединение двух согласных. Такое определение несмотря на то, что оно давно было опровергнуто Л.В. Щербой, употребляется в лингвистических работах до сих пор. ... аффриката - это не 
сочетание двух согласных, а один согласный, хотя и сложный в отношении способа образования шума» (Зиндер, 1979:140-141)

В процессе произнесения турками аффрикаты /ц/ часто наблюдается потеря её смычного элемента и произнесение только щелевого /c/. В данном случае важно научить учащихся осмысленно фиксировать начальную позицию аффрикаты. Н.А. Любимова описывает артикуляцию однофокусной переднеязычной глухой твердой фонемы [ц] следующим образом: «кончик языка находится у нижних зубов, передний участок спинки языка упирается в верхние передние зубы и альвеолы, образуя плотную энергичную смычку; спинка языка имеет ровную поверхность. Задний её участок вместе с корнем оттянут назад. Затем смычка плавно раскрывается: между передним участком спинки языка и верхними передними зубами открывается проход для выходящей воздушной струи, как при щелевом свистящем согласном. Губы нейтральны, слегка приоткрыты. Незначительно могут быть видны зубы. Мягкое небо поднято. Голосовые связки не напряжены и не колеблются» (Любимова, 2011:115)

Среди турецких учащихся владеющих лазским языком в данном случае можно наблюдать эффект положительной интерференции этого языка на русский, так как в лазской фонетической системе существует аффриката /ц/. Это яркий пример положительного влияния третьего языка на процесс формирования фонетической системы изучаемого языка.

1.5.Следующим трудноусвояемым моментом является редукция, в частности качественная редукция гласных в русском языке. Редукция гласных в русском языке крайне сложный пример позиционных изменений гласных. Выделяют два вида редукции: количественную - потеря долготы и силы звука и качественную - частичная потеря признаков звука. Примеры количественной редукции, иногда очень сильной, доходящей до нуля, существуют в турецком языке. (Аксан, 1978:46, 56) Качественная же редукция не встречается.

Вопрос редукции тесно связан с вопросом об ударении. «Слабоцентрализующий характер тюркского ударения не приводит к качественной редукции гласных, поэтому напряженность не является релевантным для ударения в тюркских языках. В русском языке гласный ударного слога характеризуется большей напряженностью, безударная позиция является слабой, приводящей к качественной редукции гласного» (Баданова, 2007). Степень редукции в русском, в первую очередь, зависит от положения гласного к ударению. По отношению к ударению различают 3 
позиции: 1-ая - ударная, 2-ая - предударная, 3-я заударная, где 1-ая позиция самая сильная, 2-ая менее и 3-тья - самая слабая. Таким образом величина редукции, т.е. потеря качества звука, соответствует цифровому обозначению её позиции. Однако процесс редукции гораздо более сложное фонетическое явление, чем простая отдаленность от ударения. Появление аллофонов фонем происходит также под действием аккомодации к соседним звукам, особенно по отношению к согласным. Н.А. Любимова отмечает, что «ярким примером аккомодации является произнесение дифтонгоидных гласных после мягких согласных, а также более передний характер артикуляций гласных заднего ряда в соседстве с мягкими согласными (люди, мёд, мять)... Согласно данным Л.А. Вербицкой, носители языка различают только те позиционнокомбинаторные аллофоны гласных, которые образуются в зависимости от твердых или мягких согласных» (Любимова, 2011:202). Таким образом в русском языке, помимо отношения к ударному слогу, принято выделять позиционные условия аллофонов по отношению к предыдущему и последующему согласным.

Основываясь на опыте работы в тюркоговорящей аудитории можно отметить, что наибольшую трудность реализации на практике представляют аллофоны фонем /o/ и /e/. Это в первую очередь связанно с тем, что орфография русского языка является этимологической и процессы редукции в ней не отображаются. Фонемы /o/ и /e/ в русском языке существуют только под ударением. В безударных позициях фонема /o/ заменяется фонемами /a/ или /i/, а фонема /e/ фонемами /i/ или /a/. По сути эти чередования и характеризуют русскую литературную речь, проявляющуюся в виде аканья и иканья. Аканьем называется процесс реализации морфонемы $\mid$ о под ударением через фонему /o/, а без ударения через фонему /a/. Иканьем же называется процесс реализации морфонем $|\mathrm{i}|,|\mathrm{e}|,|\mathrm{a}|$ и $|\mathrm{o}|$ после мягких согласных через аллофон [1]. В русском языке существуют следующие аллофоны фонемы /o/ и /e/:

\begin{tabular}{|l|l|l|l|l|l|l|l|l|}
\hline & \multicolumn{3}{|c|}{ 1-ая позиция } & \multicolumn{3}{c|}{ 2-ая позиция } & \multicolumn{2}{c|}{ 3-ья позиция } \\
\hline Фонем & Между & Между & В нач. & После & Пос & После & После & После \\
а & твердым & мягкими & слова & твердых & ле & мягки & твердой & мягкой \\
& и & согласны & & парных & /ж/ и & х & согласн & согласно \\
& согласны & ми & & согласн & /ш/ & & ой & й \\
& ми & & & ых и /ц/ & & соглас & & \\
& & & & & & & & \\
\hline
\end{tabular}




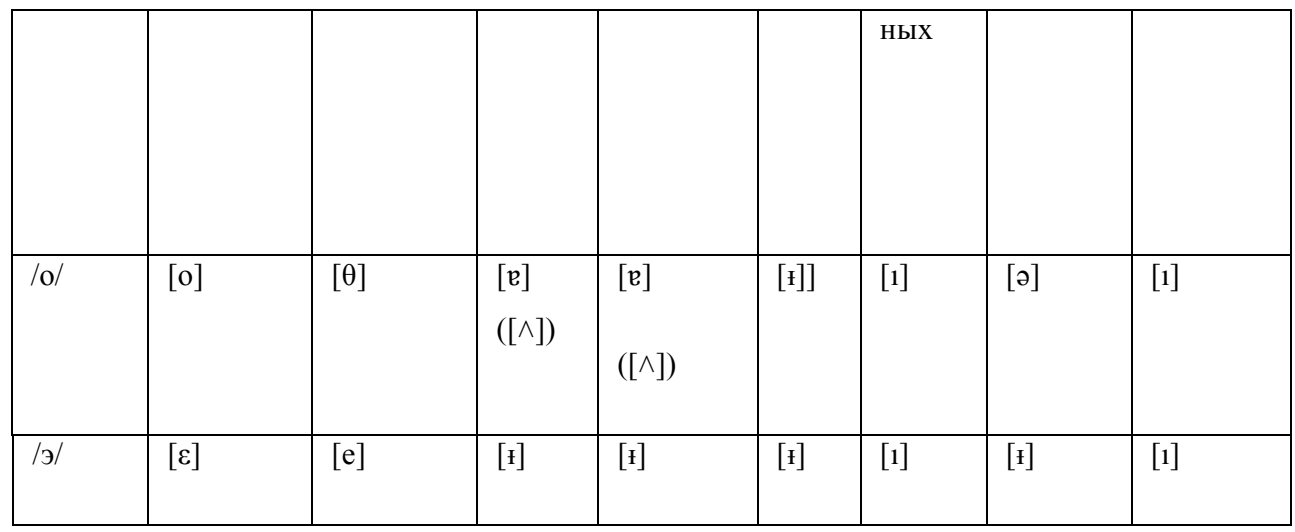

Н.А. Любимова отмечает, что в качестве рекомендаций по постановке того или иного гласного лингвистически и методически оправданно учить постановке звука в изолированной позиции, что безударная позиция рассматривается, как неблагоприятная, учитывая, что длительность безударного гласного значительно меньше и мускулатура речевых органов напряжена также меньше. (Любимова, 2011:203). Так или иначе, в процессе обучения переход к постановке безударных гласных наиболее оправдан, только после того, как поставлено произношение гласного в сильной позиции. Учитывая, что редукция в русском языке в первую очередь является результатом сильного централизованного ударения, которое отсутствует в турецком, в процессе обучения оправданно уделять внимание постановке ударения, а именно длительности ударных гласных. «Длительность ударных гласных , является обязательным основным параметром словесного ударения в русском языке» (Баданова, статья). В результате утрированного удлинения и усиления ударных гласных создаются непроизвольные физиологические условия для редукции гласных.

1.6. В конечной позиции турецких слов не встречается лабиализованный гласный /o/. «Примеры наличия лабиализованного /o/ в турецком слове в конце говорят о его иностранном происхождении» (Эргенч, 1989:15). С другой стороны «ударение в турецком языке как правило падает на конечный гласный» (Эргенч, 1989:42). Исключения из этого правила можно наблюдать среди имён собственных и заимствований. Таким образом в турецком языке создаются условия отсутствия ударного конечного гласного /o/. В русском же языке ударный гласный /o/ в конце слова встречается довольно часто. И как следствие вышеуказанного в процессе преподавания 
русского языка в турецкой аудитории часто наблюдается непроизвольное смещение ударения в таких словах как хорошо, молоко, окно, тепло, оно и др. с последнего слога на предыдущие.

\section{Заключение}

Формирование, корректировка и совершенствование правильных слухопроизносительных навыков в процессе преподавания русского языка иностранным студентам являются необходимыми для всестороннего совершенного овладения языком. Для достижения максимального результата в постановке произношения важно определить несоответствия фонетических систем родного и иностранного языков и исходя из этого уделять больше внимания разностям этих систем. Среди особенностей фонетической системы русского языка актуальных в процессе преподавания русского языка турецким студентам можно отметить: общую регрессивную направленность фонетических процессов, наличие несуществующей в турецком языке аффрикаты /ц/, наличие согласного /ж/ в виде какуминального твердого, сильное централизованное ударение в словах и как следствие качественную редукцию безударных гласных. 


\section{Библиография}

Avanesov, Ruben. Russkiye literaturnoye proiznoşeniye. Moskova: Prosveşçeniye, 1968.

Badanova, Tatyana. Akustiçeskiye parametrı slovesnogo udareniya $v$ russkom, altayskom i drugih tyurkskih yazıkah. Vesnik molodıh uçenıh. 4.sayı. 2007. 05.01.2014. http://e-lib.gasu.ru/vmu/arhive/2007/01/index.shtml

Ergenç, İclal. Spoken Language and Dictionery of Turkish Articulation. İstanbul: Multilindual, 2002. 1989.

Ergenç, İclal. Türkiye Türkçesinin Görevsel Sesbilimi. Ankara: AÜ Yayınları,

Hatioğlu, Vecihe. Türk kelimelerin Ön Sesleri. Ankara: TDK, 1961.

Lyubimova, Nina. Lingvistiçeskiye osnovi obuçeniya artikulyatsii russkih zvukov. Moskova: Russkiy yazık kurs1, 2011.

Selen, Nevin. Söyleyiş Sesbilimi, Akustik Sesbilim ve Türkiye Türkçesi. Ankara: TDK, 1979.

Şçerba, Lev. İzbrannıye rabotı po russkomu yazıku. Moskova: Press, 2007.

Şçerba, Lev. Russkiye glasnlye v kaçestvennom i koliçestvennom otnoşenii. Leningrad: Nauka, 1983.

Zinder, Lev. Obşçaya fonetika. Moskova: Vısşaya şkola, 1979. 